\title{
Performance of 3Y-TZP Bioceramics Under Cyclic Fatigue Loading
}

\author{
Renato Chaves Souza ${ }^{\mathrm{a}}$, Claudinei dos Santos ${ }^{\mathrm{a} *}$, Miguel Justino Ribeiro Barboza ${ }^{\mathrm{a}}$, \\ Carlos Antonio Reis Pereira Baptista ${ }^{\mathrm{a}}$; Kurt Strecker ${ }^{\mathrm{b}}$, Carlos Nelson Elias ${ }^{\mathrm{c}}$ \\ ${ }^{a}$ Escola de Engenharia de Lorena - EEL, Universidade de São Paulo - USP, \\ Pólo Urbo-Industrial, Gleba AI6, CP 116, 12600-970 Lorena - SP, Brazil \\ ${ }^{\mathrm{b}}$ Departamento de Engenharia Mecânica - DEM, \\ Universidade Federal de São João del-Rei-UFSJ, Praça Frei Orlando, 170, \\ 36307-352 São João del Rei - MG, Brazil \\ 'Instituto Militar de Engenharia - IME, \\ Praça General Tibúrcio, 80, Praia Vermelha, 22290-270 Rio de Janeiro - RJ, Brazil
}

Received: September 27, 2007; Revised: March 13, 2008

\begin{abstract}
In this work, the static mechanical properties and cyclic fatigue life of $3 \mathrm{~mol}$. (\%) $\mathrm{Y}_{2} \mathrm{O}_{3}$-stabilized tetragonal zirconia polycrystalline (3Y-TZP) ceramics were investigated. Pre-sintered samples were sintered in air at $1600{ }^{\circ} \mathrm{C}$ for 120 minutes, and characterized by $\mathrm{X}$ ray diffraction and scanning electronic microscopy. Hardness and fracture toughness were determined by Vicker's indentation method, and Modulus of Rupture was determined by four-point bending testing. Fully dense sintered samples, near to $100 \%$ of theoretical density, presented hardness, fracture toughness and bending strength of $13.5 \mathrm{GPa}, 8.2 \mathrm{MPa} \cdot \mathrm{m}^{1 / 2}$ and $880 \mathrm{MPa}$, respectively. The cyclic fatigue tests were also realized using four-point bending testing, within a frequency of $25 \mathrm{~Hz}$ and stress ratio $\mathrm{R}$ of 0.1 . The increasing of load stress lead to decreasing of the number of cycles and the run-out specimens number. The tetragonal-monoclinic $(\mathrm{t}-\mathrm{m}) \mathrm{ZrO}_{2}$-transformation observed by $\mathrm{X}$ ray diffraction contributes to the increasing of the fatigue life. The $3 \mathrm{Y}-\mathrm{TZP}$ samples clearly presents a range of loading conditions where cyclic fatigue can be detected.
\end{abstract}

Keywords: dental materials, $3 Y-T Z P$, mechanical properties, fatigue

\section{Introduction}

Fatigue behavior which occurs below the critical failure strength is a common phenomenon in all materials including ceramics ${ }^{1}$. The existence of cyclic fatigue effects was observed in ceramic materials, and experimental evidence was reached for a limited range of test conditions ${ }^{2}$.

The use of structural ceramics as biomaterials started in the 1970 'ies and recently, an important increasing of the importance of these materials are resulting of its use as dental materials, because ceramics present attractive advantages such as aesthetic, biocompatibility and chemical inertness ${ }^{3-5}$. Zirconium oxide, $\mathrm{ZrO}_{2}$, is a promising bioceramic due to its excellent biocompatibility, high fracture strength, fracture toughness, and low Young's modulus ${ }^{6-9}$. It is knowledge that $\mathrm{ZrO}_{2}$ additions may increase the fracture toughness of compatible ceramic materials. This effect is based on the tetragonal to monoclinic phase transformation of $\mathrm{ZrO}_{2}$, associated to the increasing of the grains around 3 and 5 vol. $(\%)^{9}$. This volumetric expansion generates stresses in the ceramic matrix, which difficult the crack propagation. When this ceramic is used for implants such as artificial joints or dental abutment, it undergo loading for fairly long period ${ }^{10}$.

There is a strong demand for generation of design-relevant fatigue data. On the other hand, knowledge of fatigue in ceramics is insufficient so $\operatorname{far}^{11,12}$. Furthermore, fatigue testing applied to brittle materials imposes a number of problems. One of them is wide scatter in data, which sometimes obscures the fatigue tendency. This scatter is considered to derive intrinsically from a defect distribution in the specimens ${ }^{13}$.

In this paper, the physical and mechanical properties of the commercial 3 mol.\% $\mathrm{Y}_{2} \mathrm{O}_{3}$-tetragonal zirconia polycrystals (3Y-TZP) were investigated. Furthermore, the performance of these ceramics under cyclic fatigue loading was determined using four-point bending testing.

\section{Experimental Procedure}

High-purity pre-sintered $\mathrm{ZrO}_{2}-3$ mol. $\% \mathrm{Y}_{2} \mathrm{O}_{3}$ ceramic blocks (ProtMat - Brazil) were sintered in air at $1600{ }^{\circ} \mathrm{C}$ for 2 hours, with heating and cooling rate of $10{ }^{\circ} \mathrm{C} /$ minute.

Bulk density was measured by the Archimedes' method in distilled water. The crystalline phases present in sintered surfaces, were determined $\mathrm{X}$ ray diffractometry using $\mathrm{Cu}-\mathrm{k} \alpha$ radiation in the $2 \theta$ range of 20 to $80^{\circ}$, with a step width of $0.05^{\circ}$ and 2 seconds of exposure time per position. The monoclinic phase content of different surfaces was calculated using the Garvie and Nicholson method ${ }^{14}$ :

$$
X_{m}=\frac{I_{m(\overline{1} 1)}+I_{m(111)}}{I_{m(\overline{1} 11)}+I_{m(111)}+I_{t(101)}}
$$

where, $\mathrm{I}_{\mathrm{t}}$ and $\mathrm{I}_{\mathrm{m}}$ represent the integrated intensity (area under the peaks) of the tetragonal (101) and monoclinic $(111)_{\mathrm{m}}$ and $(111)_{\mathrm{m}}$ peaks. The monoclinic volume fraction was then obtained using equation proposed by Toraya et al. ${ }^{15}$ :

$$
\mathrm{V}_{\mathrm{m}}=\frac{1.311 \mathrm{X}_{\mathrm{m}}}{1+0.311 \mathrm{X}_{\mathrm{m}}}
$$

A total of 20 specimens sized on $3 \times 4 \times 45 \mathrm{~mm}$ were machined from the as-received plates and subsequently grinded and polished to $1 \mu \mathrm{m}$ diamond surface finish.

For microstructural characterization, the polished surfaces with subsequent thermal etching $\left(1350{ }^{\circ} \mathrm{C}-15\right.$ minutes $)$ of the sintered samples and fractured surfaces of the mechanically tested specimens were examined by scanning electron microscopy (SEM), using LEO-1450VP microscope. 
Hardness and fracture toughness, $\mathrm{K}_{\mathrm{IC}}$, were determined using a Vickers Indentation method. In each sample, 10 indentations were measured, under a load of 2000 gf for 30 seconds. The fracture toughness has been calculated by measurement of the relation between cracks length (c) and indentation length (a), using the relation proposed by Niihara et al. ${ }^{16}$, valid for Palmqvist crack types, which present c/a relation $<3.5$.

The modulus of rupture (MOR) was determined by four-point bending testing, using a four-point bending device with outer and inner spans of 40 and $20 \mathrm{~mm}$, respectively. The crosshead displacement speed was $0.5 \mathrm{~mm} /$ minute at room temperature, using a testing machine MTS $810(250 \mathrm{kN})$.

Cyclic fatigue tests were realized by four-point bending loading in air at room temperature and studied under a sinusoidal stress wave form with a frequency of $25 \mathrm{~Hz}$ and a constant stress ratio (R) of 0.1 . A total of 61 specimens with size of $3 \times 4 \times 45 \mathrm{~mm}$ were machined from the as-received plate and polished to $1 \mu \mathrm{m}$ diamond surface finish. The number of specimens used in fatigue tests varied between 13 and 23 samples under stresses of 570, 610 and $650 \mathrm{MPa}$. At $550 \mathrm{MPa}$, at least 6 specimens were tested. In the lower stress levels, 500 and 530, at least 3 specimens were tested. The tests were interrupted when the surviving samples reached a number of stress cycles between 2 and $5 \times 10^{6}$ cycles $^{17}$.

To avoid the effect of the surface finishing on the mechanical properties, the roughness of the polished surfaces were measured for all samples, using a Mitutoyo SJ-201 Surface Roughness Tester, in the both longitudinal and transverse directions.

\section{Results and Discussion}

\subsection{Characterization}

Figure 1 presents $\mathrm{X}$ ray diffractogram patterns of the polished surface after sintering and fracture surface after bending testing.

After sintering, the processing conditions used in this work allowed a total stabilization of tetragonal $\mathrm{ZrO}_{2}$ phase. The $\mathrm{X}$ ray diffraction patterns of the fractured surfaces of the bending tested samples show a significant monoclinic phase content (near to 10 vol. (\%)), result of the stress-induced t-m transformation, due to crack propagation. It is known that the application of stresses to tetragonal $\mathrm{ZrO}_{2}$ grains may start the $\mathrm{t}-\mathrm{m}$ transformation ${ }^{4}$.

Figure 2 presents micrographs of polished/etched $\mathrm{ZrO}_{2}$ surface and fracture surface of a sample tested in fatigue testing.

In Figure 2a, the presence of refined microstructure with equiaxial grains of mean size smaller than $0.5 \mu$ m was observed. Furthermore, no abnormal grain growth of $\mathrm{ZrO}_{2}$ was detected in this sintered material. In Figure 2b a typical brittle fracture surface which clearly shows that the initial crack nucleation and propagation region are located in the upper side of the picture, corresponding to the region of maximum tensile stress in the fatigue test.

The roughness results, relative density and mechanical properties of the sintered samples are listed in Table 1.

The high densification ( $>99.5 \%$ of T.D.) of the sintered samples indicates that the sintering conditions used in this work contributed to eliminate porosity maintaining a microstructure with fine grains, Figure 2a. This typical microstructure and the XRD patterns, showed in Figure 1a, indicate the predominance of tetragonal phase, justifying the high $\mathrm{K}_{\mathrm{IC}}$ and MOR values presented in Table 1. Majority, $\mathrm{t}-\mathrm{m}$ phase transformation is the main toughening mechanism, which, associated with crack deflection were the responsible by the improvement of the mechanical properties of this material. The high bending strength presented for sintered samples, near to $900 \mathrm{MPa}$, are related to the high tetragonal content, associated with fine $\mathrm{ZrO}_{2}$ grains and low porosity. Furthermore, the hardness and fracture toughness values were about 13.5 GPa and 8.2 $\mathrm{MPam}^{1 / 2}$, respectively. These results are consistent with previously related literature data ${ }^{9,11,12}$ for 3 Y-TZP ceramics.

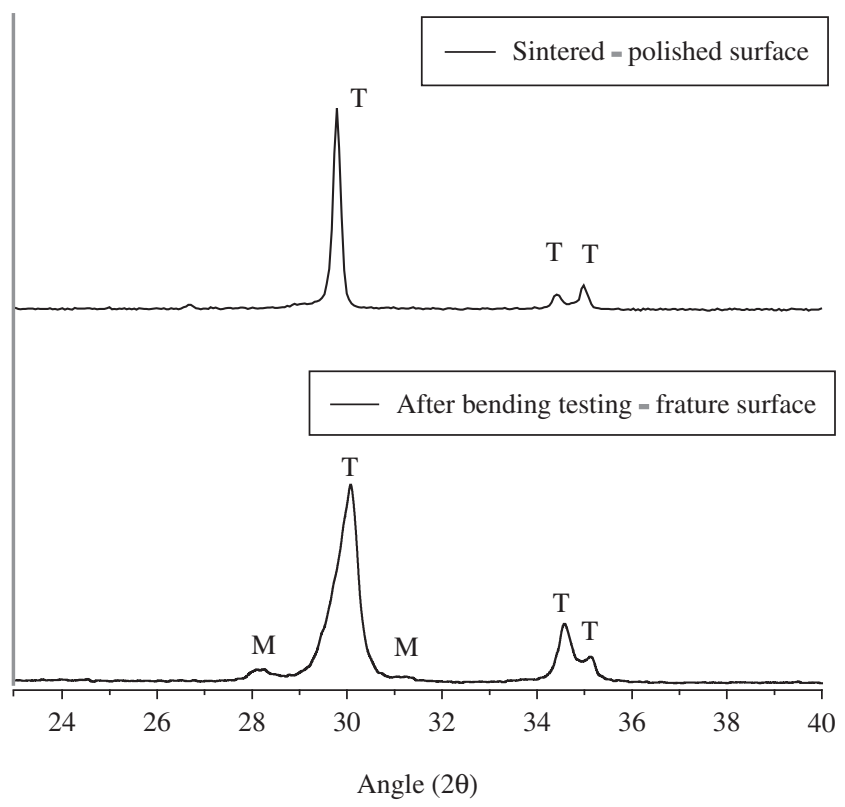

Figure 1. $\mathrm{X}$ ray diffractogram patterns: a) polished surface after sintering at $1600^{\circ} \mathrm{C}$ and $\mathrm{b}$ ) fracture surface after bending testing. ( $\mathrm{T}$ - tetragonal; $\mathrm{M}$ - monoclinic).

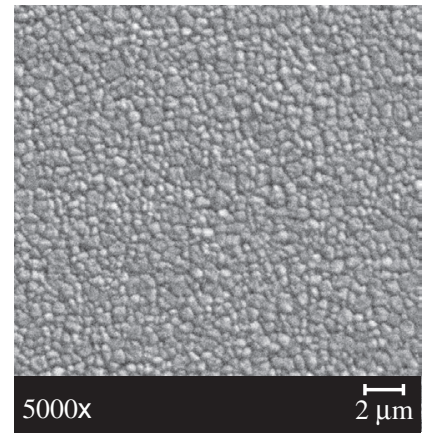

(a)

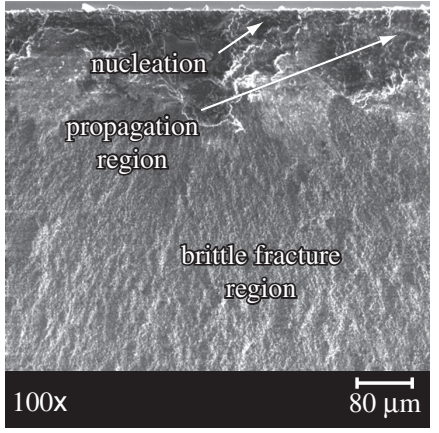

(b)
Figure 2. SEM micrograph of the 3Y-TZP ceramics: a) polished surface, and b) fractured surface.

Table 1. Properties of the 3Y-TZP sintered samples.

\begin{tabular}{cccccc}
\hline $\begin{array}{c}\text { Relative density } \\
(\%)\end{array}$ & $\begin{array}{c}\text { Vickers hardness } \\
(\mathrm{GPa})\end{array}$ & $\begin{array}{c}\text { Fracture toughness } \\
\left(\mathrm{MPam}^{1 / 2}\right)\end{array}$ & $\begin{array}{c}\text { Modulus of rupture } \\
(\mathrm{MPa})\end{array}$ & \multicolumn{2}{c}{ Roughness } \\
\cline { 4 - 6 } & $13.5 \pm 0.2$ & $8.15 \pm 0.25$ & $880 \pm 35$ & $0.04 \pm 0.01$ (Longitudinal) & $0.42 \pm 0.15$ (Longitudinal) \\
$99.7 \pm 0.2$ & & & $0.15 \pm 0.04$ (Transverse) & $0.45 \pm 0.05$ (Transverse) \\
\hline
\end{tabular}


The bending strength $\sigma_{\mathrm{f}}$ of the ceramic is directly proportional to the toughness $\mathrm{K}_{\mathrm{IC}}$ as predicted by linear elastic fracture mechanics ${ }^{18}$ :

$$
\sigma f=\frac{K_{\mathrm{IC}}}{\mathrm{Y} \sqrt{\mathrm{C}}}
$$

where $\mathrm{Y}$ is the geometric factor corresponding to $2 / \sqrt{\pi}=1.128$, and $\mathrm{C}$ can be considered alternatively to be the flaw size initiating fracture. Then, the flaw sizes initiating fracture of the $\mathrm{ZrO}_{2}$ ceramics sintered at $1600{ }^{\circ} \mathrm{C}$ are estimated to be between 58.5 and $77.6 \mu \mathrm{m}$, considering the standard deviation of the results presented in Table 1 . These critical flaw sizes indicate that the $\mathrm{ZrO}_{2}$ ceramic is durable against machining flaws between 55 and $80 \mu \mathrm{m}$, which are expected to occur during the preparation of the restorations using a high-speed handpiece, in an usual range of 20 to $50 \mu \mathrm{m}^{18}$, indicating that the machining flaw size in this material must be lower than $20 \mu \mathrm{m}$. Furthermore, an uniform preparation of the tensile surfaces, submitted to the bending testing and cyclic fatigue loading testing, attested by the roughness results $\left(\mathrm{R}_{\mathrm{a}}<0.15 \mu \mathrm{m}\right.$ and $\left.\mathrm{R}_{\max }=0.45 \mu \mathrm{m}\right)$, indicates that the effect of the surface finishing is negligible in the bending strength and fatigue results. The results of the cyclic fatigue tests represented as function of the stress $x$ number of cycles $(\sigma \times N)$, are shown in Figure 3.

The cyclic fatigue tests were interrupted at $\mathrm{N}_{\mathrm{f}}=5 \times 10^{6}$ cycles, for samples whitout failre. These samples are marked an arrow symbol. Five maximum stress levels $\left(\sigma_{\max }\right)$ were selected in relation to the initial strength obtained under static tests. It was found that fatigue strength limit is around $550 \mathrm{MPa}$, which corresponds to $62.5 \%$ of the MOR.

At the lowest stress levels $\left(\sigma_{\max }=500 \mathrm{MPa}\right.$ and $\left.530 \mathrm{MPa}\right)$, neither spontaneous nor fatigue fracture were observed. As $\sigma_{\max }$ increased, some specimens reached $\mathrm{N}_{\mathrm{f}}=2 \times 10^{6}$ cycles without failure, but some specimens, failed spontaneously, i. e., below $10^{3}$ loading cycles. On the other hand, the number of specimens failing at $10^{3}<\mathrm{N}_{\mathrm{f}}<2 \times 10^{6}$ was relatively large. For 13 specimens tested at $\sigma_{\max }=650 \mathrm{MPa}, 4$ specimens failed below a hundred cycles, 9 failed during cycling and none achieved $10^{6}$ cycles. The 23 specimens tested at $\sigma_{\max }=610 \mathrm{MPa}$ revealed the following: 1 specimen failed below a hundred cycles, 19 failed during cycling,

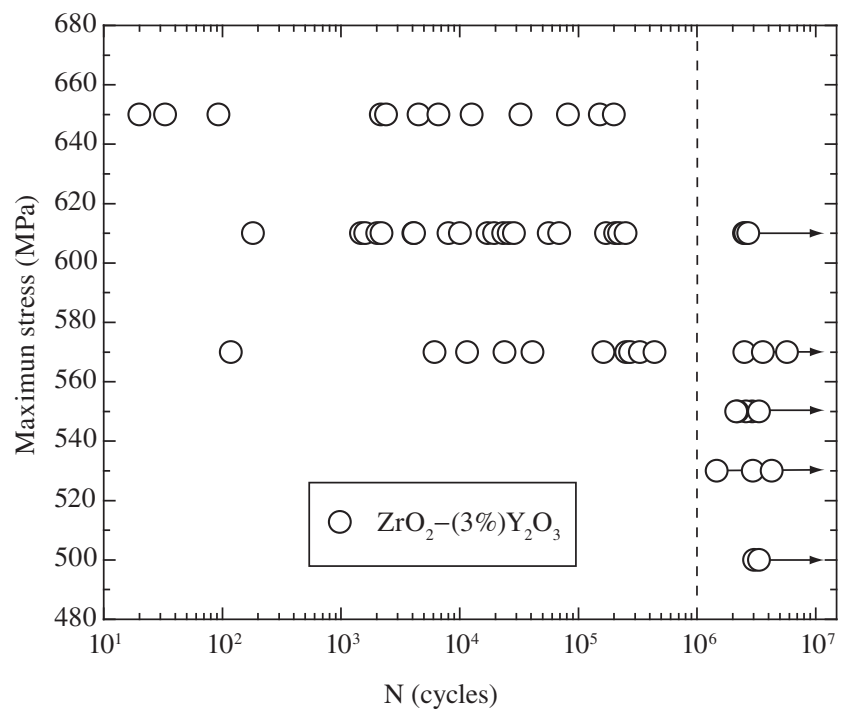

Figure 3. Cyclic fatigue tests results of the 3Y-TZP samples: $\sigma_{\max } \times N$ curve.
3 specimens survived $2 \times 10^{6}$ cycles. The 13 specimens tested at $\sigma_{\max }=570 \mathrm{MPa}$ revealed that 1 specimen failed below hundred cycles, 9 failed during cycling, 3 specimens survived $2 \times 10^{6}$ cycles. At stress levels above of $550 \mathrm{MPa}$, the most of specimens failed in the range of $10^{3}<\mathrm{N}_{\mathrm{f}}<2 \times 10^{6}$ cycles. Samples with low cycle failure $\left(\mathrm{N}_{\mathrm{f}}<10^{3}\right.$ cycles $)$, have a trend to be more representative of bigger stresses, while the reduction of maximum stress applied lead to a significant increasing of the number of samples without failure $\left(\mathrm{N}_{\mathrm{f}}>2 \times 10^{6} \text { cycles }\right)^{17}$

The specimens rupture in fatigue starts in the polished tensile surface of the sample and occur in a brittle mode, being a function of the critical flaw size. This flaw must overcome the compression stresses generated by martensitic transformation in order to propagate. The $\mathrm{t}-\mathrm{m}$ transformation, as also was observed by Grathwohl and $\mathrm{Liu}^{11}$, increases the critical flaw size and results improved strength and fatigue resistance.

\section{Conclusions}

In this work, dense 3 Y-TZP ceramics were obtained after sintering at $1600{ }^{\circ} \mathrm{C}$. Based on the high densification, refined microstructure composed of $\mathrm{ZrO}_{2}$ - grains with average size around $0.5 \mu \mathrm{m}$ and high tetragonal phase content, this ceramic presented hardness, fracture toughness and bending strength of $13.5 \mathrm{GPa}, 8.15 \mathrm{MPa}^{1 / 2}$ and $880 \mathrm{MPa}$, respectively.

The low roughness (near to $0.45 \mu \mathrm{m}$ ) of the polished tensile surface submitted to the bending testing minimized the effect of this behavior in the bending strength and cyclic fatigue results. Furthermore, this low-roughness typical surface can to minimize the bacterial colonization dental biofilm formation on the ceramics.

The primary cyclic fatigue evaluation indicates a strong propensity for fatigue behavior, presenting a considerable range of loading conditions, where cyclic fatigue can be detected. It was found that the fatigue strength limit is lower than $550 \mathrm{MPa}(62.5 \%$ of the MOR).

\section{Acknowledgments}

The authors acknowledge to the FAPESP for financial support, under Grants n ${ }^{\circ}$ 04/04386-1 and 05/52971-3.

\section{References}

1. Basu D, Sarkar BK. Effect of zirconia addition on the fatigue behaviour of fine grained alumina. Bulletin Material Science. 2001; 24(2): 101-104.

2. Grathwohl G, Liu T. Strengthening of zirconia-alumina during cyclic fatigue testing. Journal American Ceramic Society. 1989; 72(10): 1988-1990

3. Hench LL, Wilson J. An Introduction to Bioceramic. Advanced Series in Ceramics. Singapore: World Scientific; 1993; 1: 1-23.

4. Willians DF. Medical and Dental Materials. New York: VCH Weinheim; 1992.

5. Hench LL. Bioceramics. Journal American Ceramic Society. 1998; 81(7): 1705-1728.

6. Basu B, Vleugels J, Van Der Biest $\mathrm{O} . \mathrm{ZrO}_{2}-\mathrm{Al}_{2} \mathrm{O}_{3}$ composites with tailored toughness. Jounal Alloys and Compounds. 2004; 372(1-2): 278-284.

7. De Aza AH, Chevalier J, Fantozzi G, Schehl M, Torrecillas R. Crack growth resistance of alumina, zirconia and zirconia toughened alumina ceramics for joint prostheses. Biomaterials. 2002; 23(3): 937-945.

8. Piconi C, Maccauro G. Zirconia as a ceramic biomaterial. Biomaterials. 1999; 20(1): 1-25.

9. Stevens R. An Introduction to Zirconia: Zirconia and Zirconia Ceramics. $2^{\text {nd }}$ ed. New York: Magnesium Electrum, Twickenham; 1986. (Magnesium Elektron Publications, n113). 
10. Zhu P, Lin Z, Chen G, Kiyohiko I. The predictions and applications of fatigue lifetime in alumina and zirconia ceramics. International Journal Fatigue. 2004; 26(10): 1109-1114.

11. Grathwohl G, Liu T. Crack resistance and fatigue of transforming ceramics: $\mathrm{I}$, materials in the $\mathrm{ZrO}_{2}-\mathrm{Y}_{2} \mathrm{O}_{3}-\mathrm{Al}_{2} \mathrm{O}_{3}$ system. Journal American Ceramic Society. 1991a; 74(2): 318-325.

12. Grathwohl G, Liu T. Crack resistance and fatigue of transforming ceramics: II, $\mathrm{CeO}_{2}$-stabilized tetragonal $\mathrm{ZrO}_{2}$. Journal American Ceramic Society. $1991 b ; 74$ (12): 3028-3034.

13. Kawakubo T, Komeya K. Static and cyclic fatigue behavior of a sintered silicon nitride at room temperature. Journal American Ceramic Society. 1987; 70(6): 400-405.

14. Garvie RC, Nicholson PS. Phase analysis in zirconia systems. Journal American Ceramic Society. 1972; 55(6): 303-305.
15. Toraya H, Yoshimura M, Somiya S. Calibration curve for quantitative analysis of the monoclinic tetragonal $\mathrm{ZrO}_{2}$ system by X-ray diffraction. Journal American Ceramic Society. 1984; 67(6): 119-121.

16. Niihara K, Morena R, Hasselman DPH. Evaluation of KIC of brittle solids by the indentation method with low crack-to-indent ratios. Journal of Materials Science Letters. 1982; 1(1): 13-16

17. Wu F, Lai T, Zhuang H, Wang P, Fu X. $\alpha / \beta$-Sialon ceramics and its fatigue life. Materials Letters. 1999; 39(4): 197-199.

18. Kim D-J, Lee M-H, Lee D-Y, Han J-S. Mechanical properties, phase stability, and biocompatibility of (Y,Nb)-TZP/A12O3 composite abutments for dental implant, Journal Biomedical Materials Research Part B. 2000, 53(4): 438-443. 